\title{
OS MEANDROS DA EDUCAÇÃO E DA APRENDIZAGEM EM MEIO À PANDEMIA COVID-19: OS DESAFIOS E AS LIÇÕES
}

\section{THE EDUCATION AND LEARNING MEANS OF PANDEMIC COVID-19: THE CHALLENGES AND LESSONS}

\author{
Hercules Guimarães Honorato ${ }^{1}$, \\ ${ }^{1}$ Escola Superior de Guerra, Departamento de Ensino, Brasil, e-mail: hghhhma@gmail.com, ORCID: \\ https://orcid.org/0000-0001-7340-1532
}

\author{
ARTICLE INFO \\ Article history: \\ Received 2020-05-17 \\ Accepted 2020-12-12 \\ Available online 2020-12-12
}

Palavras-chave: Aprendizagem. Educação a distância. Ensino Remoto. Escolas fechadas. Pandemia COVID19.

Keywords: Learning. Distance learning. Remote Teaching. School closing. COVID-19 Pandemic.

RESUMO. O presente estudo tem por objetivo apresentar as lições que estão surgindo como possíveis ações a serem empreendidas pelos gestores escolares, professores e legisladores de políticas públicas durante o fechamento das escolas devido à Pandemia COVID-19. Os aspectos abordados são do campo da educação, alinhavados com a educação a distância e no aprendizado do alunado nesse período em questão. A abordagem foi qualitativa, com pesquisas documental e bibliográfica como técnicas exploratórias iniciais. A coleta de dados foi via survey on-line, cujo link foi encaminhado às redes sociais deste autor na internet. $O$ artigo está estruturado em quatro seções principais: a primeira trata da metodologia; a seguinte apresenta o quadro teórico; a terceira discute a educação e a pandemia; e a última seção apresenta as análises dos dados levantados. Ao final, as seguintes lições foram destacadas, em especial: (i) os professores não estavam preparados para o ensino remoto; (ii) democratizar o acesso à internet e conduzir orientações de aprendizado e aulas por meio do uso da televisão aberta, telefone e rádio; (iii) incluir, no Projeto Político Pedagógico e nos currículos, alternativas de ensino, aprendizagem e avaliação para um período escolar anormal; (iv) avaliar as Diretrizes Curriculares Nacionais e os currículos de formação dos professores com a inclusão de disciplinas obrigatórias ligadas a tecnologias educacionais; e (v) rever os marcos regulatórios da EAD para sua utilização na educação básica. A passagem das atividades formais e presenciais para a virtual, infere-se que trará diversas consequências, em especial deverá haver aumento nas desigualdades educacionais.

\begin{abstract}
The present study presents lately lessons learned as how to issue public policies by school managers, professors, and legislators to counter the COVID-19 pandemic. The targeted aspects are education field focused, inherently connected with distance learning during this period. The approach is qualitative having documental and bibliographic research as initial exploratory techniques. The data collection was through an on-line survey divulged by social networks. The paper is structured in four main sections: the first about methodology, the second covering the surrounding introductory picture, the third discussing education and its relation with the pandemic, and the last section presenting the analysis on the collected data. At last, the following main lessons are outlined: (i) professors were not ready for the distance teaching; the importance of (ii) democratizing the access to the internet, and performing learning through open television, telephone and radio; (iii) including on the curriculum and politic-pedagogic project teaching, learning and evaluation alternatives for an abnormal school period; (iv) properly evaluating the Nacional Curriculum Directives and including education techniques disciplines on the teacher training curricula; and ( $v$ ) reviewing the regulatory policies on distance learning for basic education. The transition from formal and face-to-face activities to the virtual one implies several consequences, in particular, there should be an increase in educational inequalities.
\end{abstract}




\section{Introdução}

O bom senso é a coisa melhor dividida no mundo, pois cada um se julga tão bem dotado dele que ainda os mais difíceis de serem satisfeitos em outras coisas não costumam querêlo mais do que têm. (Rene Descartes)

O ser humano não nasce pronto para trilhar o seu caminho de vida, ele necessita dos seus pares para a sua formação. A gênese da formação sócio-política do homem encaminhase por intermédio da educação, uma mediação que vai ser desenvolvida para a sua autonomia e para a sua integração social. Libâneo (2005, p.23) afirma que não existe uma natureza humana universal, os sujeitos são construídos socialmente e vão formando sua identidade, "de modo a recuperar sua condição de construtores de sua vida pessoal e seu papel transformador" dessa sociedade.

A sociedade, vista sobre o espectro amplo de uma "torre de babel", congrega um coletivo de seres humanos habitantes do planeta Terra, com diversas diferenças sentidas, começando pela língua falada, as de caráter religioso, as sociais, as políticas e até as econômicas. Porém, nos tempos atuais, ocorreu uma união de todos para o combate de um inimigo único e invisível, a partir de fevereiro de 2020, que rapidamente atravessou linhas demarcatórias fluidas, atingindo mentes e medos, o chamado novo coronavirus, ou, como ficou conhecido, o COVID-19. Alguns países decretaram o chamado "lockdown" de todas as suas atividades, que seria um rígido distanciamento social, uma medida severa tomada para tentar desacelerar a propagação do vírus.

As instituições de ensino no mundo não poderiam ficar excluídas, pararam por um período indeterminado, pois não conhecemos esse novo inimigo e o que poderá acontecer nos próximos dias e meses não se sabe. As notícias são assustadoras, o pânico arrolado com o medo de uma contaminação iminente é uma constante. Não existe notícia boa, apenas são apresentados os números de mortos e contaminados, que, segundo o placar funesto, continua a crescer.

Com essa manutenção de um discurso negativo nas redes de divulgação de notícias, associada a uma crise sanitária, comparável as situações de guerra, este autor se viu em palpitações mentais do que poderia fazer nesse momento e concluiu: estamos atualmente sem vida própria. A partir desse ponto, as informações que surrupiavam em um dia normal de sol de outono no Rio de Janeiro, foram transformadas em conhecimentos nas leituras e estudos que estivessem sendo divulgados no mundo acadêmico no campo da educação, sobrevoando a atual pandemia, e culminando em um processo de pesquisas e novos resultados a serem apresentados a discussões. 
Segundo a Organização das Nações Unidas para a Educação, a Ciência e a Cultura (UNESCO ${ }^{1}$, com mais de 1,5 bilhão de estudantes afetados pela pandemia em todo o mundo, a educação enfrenta uma crise sem precedentes, representando $87 \%$ da população mundial de estudantes. Audrey Azoulay, sua diretora-geral no Brasil, assevera que "Nós nunca antes havíamos testemunhado a interrupção educacional em uma escala como esta". O que de imediato podemos afiançar, quando foram determinadas o fechamento das escolas em um período de ano letivo, é que não estávamos preparados para tal situação, pois não havia ações efetivas e de imediata execução para a continuação do processo de ensino e aprendizagem, sem escolas e nesse novo contexto, com certeza uma disruptura mundial muito sentida.

O fechamento das escolas, retirando o estudante de um ambiente de construção social, de convívio com os demais colegas, requer uma avaliação da aprendizagem nas ações e soluções que foram e estão sendo apresentadas como possíveis de serem implementadas. Nesse contexto sem precedentes, é importante refletir sobre como enfrentar o processo educacional e como conciliá-lo com as demais áreas da vida impactadas pela emergência.

O presente estudo, portanto, tem como objetivo principal apresentar as principais lições que estão surgindo como possíveis de se transformarem em ações a serem empreendidas pelos gestores escolares, professores e legisladores de políticas públicas educacionais no que tange ao maior desafio que o mundo está vivenciando desde a $2^{\mathrm{a}}$ Guerra Mundial. Este estudo não entra nos aspectos ligados à emergência sanitária que vivemos, nem sobre o aspecto político, social e econômico da temática de um mundo pós-pandemia. Os aspectos abordados são do campo da educação e no aprendizado do alunado em questão.

O artigo está estruturado em quatro seções principais, além da Introdução e das Considerações Finais. A primeira seção trata da metodologia empregada na pesquisa. A seção seguinte apresenta o quadro teórico construído, com especial atenção aos artigos publicados sobre as ações de políticas públicas e educação a distância desenvolvidas na China. A terceira parte discute propriamente dita a educação e a pandemia, dividindo em duas subseções, uma que trata dos aspectos verificados no mundo e outra específica do Brasil. A última seção apresenta os resultados e as discussões.

Assim contextualizado inicialmente, a seguinte questão de estudo norteou este trabalho: Que lições poderiam ser aprendidas pelos envolvidos com a aprendizagem discente após a reabertura das escolas?

\footnotetext{
${ }^{1}$ Disponível em: https://pt.unesco.org/news/unesco-reune-organizacoes-internacionais-sociedadecivil-e-parceiros-do-setor-privado-em-uma. Acesso em: 28 abr. 2020.
} 


\section{Metodologia}

Esta pesquisa é de abrangência qualitativa, pois se preocupa com uma visão sistêmica do objeto de estudo, tenta explicar a realidade verificada nos desveladas por intermédio dos problemas sociopolíticos, econômicos, culturais e, em especial, os educacionais. Oliveira (2016, p.59) deixa transparente que a pesquisa qualitativa é caracterizada como "um estudo detalhado de um determinado fato, objeto, grupo de pessoas ou ator social e fenômenos da realidade [...] o pesquisador(a) deve ser alguém que tenta interpretar a realidade dentro de uma visão complexa, holística e sistêmica".

Em relação aos objetivos, a presente pesquisa se caracteriza inicialmente como exploratória, cujo propósito é "proporcionar maior familiaridade com o problema, com vistas a torná-lo mais explícito [...]" (Gil, 2010, p.27). A pesquisa exploratória foi escolhida pois o tema em estudo é pouco explorado, o que requereu um levantamento bibliográfico, análise em documentos, observações de fatos e fenômenos (OLIVEIRA, 2016). A pesquisa documental e bibliográfica buscou estabelecer relações sobre a educação e a pandemia COVID-19, com um levantamento de artigos em sítios acadêmicos na internet, que trouxessem a luz sobre o que está sendo apresentado como soluções institucionais e políticas educacionais durante o fechamento das escolas e a continuidade do ensino e aprendizagem dos estudantes.

De posse dos resultados levantados, efetuou-se uma análise do material gerado, com base nos eixos considerados - pandemia COVID-19, educação, estudante, professores, aprendizagem, família e ensino remoto.

\section{Referencial Teórico}

O levantamento do estado da arte sobre um tema conjuntural como esse contou, como não poderia deixar de ser, em matérias da crise sanitária na China e sua reação diante da maior população escolar do planeta em um território de grandes proporções. Assim, foram trabalhados dois artigos de autores chineses complementados por duas notícias de jornais.

Os artigos acadêmicos foram de Wunong Zhang et al., cujo título é "Suspending Classes Without Stopping Learning: China's Education Emergency Management Policy in the COVID-19 Outbreak"; e Longjun Zhou et al., intitulado: "School's Out, But Class's On', The Largest Online Education in the World Today: Taking China's Practical Exploration During The COVID-19 Epidemic Prevention and Control as An Example". As duas notícias diretas da China, em tradução livre, são: "Não deixe uma pessoa para trás! 9.262 estudantes pobres em 
Guangdong receberam aulas online em tablet ${ }^{2 "}$ e "O que pode ser feito para aliviar o problema de 'estudantes pobres que não podem fazer cursos online'3?

Como estamos também na "quarentena das lives", a nossa investigação caminhou por diversas entrevistas e reportagens em tempo real, mas uma teve um caráter todo especial. Este autor pode participar de uma transmissão ao vivo com professores e gestores do Chile, com a moderação do professor Fernando M. Reimers, um dos autores do e-book "Un marco para guiar una respuesta educativa a la Pandemia del 2020 del COVID-19", que tem como objetivo principal o de apoiar as tomadas de decisões no campo da educação no desenvolvimento e aplicação de respostas educativas efetivas ante a Pandemia COVID-19. $\mathrm{Na}$ live em si, diversos pontos foram discutidos com grande similaridade ao vivenciado no Brasil.

Outro importante documento foi obtido por intermédio da professora Marcela Duarte Herrera, da Universidad del Valle, da cidade de Cali, Colômbia, sobre o desenvolvimento das políticas públicas educacionais emanadas pelo seu Ministério da Educação e de caráter geral. O documento, denominado "Sector Educativo al Servicio de la vida: juntos para Existir, Convivir y Aprender" (COLÔMBIA, 2020). Um documento bem completo e detalhado que traça orientações aos diretores e professores para a prestação do serviço educacional em casa durante a emergência sanitária.

Continuando pela quarentena das lives, participamos de uma videoconferência do professor Carlos Bravo Reyes, da Universidade Autônoma Gabriel René Moreno, da cidade de Santa Cruz de La Sierra, Bolívia. A apresentação foi organizada pela Universidade do Panamá, cujo título era: "Encuentro de Educatión Virtual para Latinoamerica em tempos del COVID-19". O professor Carlos tratou do tema da "Microaprendizaje mediante el trabajo em redes sociales - el caso de facebook y WhatsApp". Um comentário interessante apresentado foi que no último ano da licenciatura em educação em sua universidade, os estudantes tem uma disciplina denominada "Tecnología educativa", assim foi-nos disponibilizado o "Rediseño de la Licenciatura em Ciências de La Educación" (UNIVERSIDAD, 2016), ou seja o currículo de formação em Ciências da Educação, e que é discutida em seção posterior.

Em relação ao que está acontecendo em nosso país para a continuação da aprendizagem dos estudantes com as escolas fechadas, fomos caminhar por uma revista recém lançada pelo Programa de Pós-Graduação em Educação da Faculdade de Educação da UFRJ, cujo título é "Em defesa da Educação Pública comprometida com a igualdade social:

\footnotetext{
2 不让一人掉队 ! 广东9262名贫困学生收到平板电. Disponível em: http://news.southcn.com/nfplus/gdiytt/content/2020-03/02/content 190475992.htm. Acesso em: 28 abr. 2020. Tradução livre.

3 拿什么纾解“贫困生无法上网课”难题?. Disponível em: https://toutiao.china.com/t 6LSr5Zuw55Sf5peg5rOV5LiK572R6K--.html. Acesso em: 28 abr. 2020. Tradução livre.
} 
porque os trabalhadores não devem aceitar aulas remotas". Outro documento utilizado foi a "Declaração pela Aprendizagem em Tempo de Pandemia" da Secretaria de Estado de Educação do Rio de Janeiro, em que são propostas estratégias de ofertas remotas de aprendizagem com a mediação tecnológica.

A Educação a Distância (EaD) ou Educação Virtual (MILL, 2012), no Brasil, também pode ser conhecida como Ensino a Distância, Treinamento a Distância, ou mesmo Educação online, este um conceito mais restrito. Para este estudo, entende-se que Educação a Distância abarca todos os demais vocábulos sem distinção. Moran (2002, p.41) também expõe seu conceito, como sendo o "conjunto de ações de ensino-aprendizagem desenvolvidas via meios telemáticos, como a internet, a videoconferência e a teleconferência". Tem-se também a expressão e-learning, outra forma utilizada para expressar a EaD fora e dentro do país.

O caminho escolhido pelas redes de ensino nos estados e municípios foi partir para o que ficou denominado de "ensino remoto". O Decreto no 9.057, de 25 de maio de 2017, regulamenta 0 art. 80 da LDB que trata especificamente da Educação a Distância (EaD). Considera-se EaD a modalidade educacional na qual "a mediação didático-pedagógica nos processos de ensino e aprendizagem ocorra com a utilização de meios e tecnologias de informação e comunicação, com pessoal qualificado, com políticas de acesso, com acompanhamento e avaliação compatíveis, entre outros [...]" (BRASIL, 2017, p.1, grifo nosso). Foi realçado por este autor que o pessoal tem que ser qualificado.

Durante a leitura do material teórico levantado, este autor elaborou uma nuvem de palavras que, em sua essência estruturante, são importantes na compreensão do objeto deste estudo. As palavras-chave, em ordem alfabética, são: alunos, aprendizagem significativa, aprendizagem da pobreza, currículo, desigualdade social, didática, Educação, Educação a Distância $(\mathrm{EaD})$, ensino remoto, escolas eficazes, estudantes, interdisciplinaridade, metodologias ativas, professor, redes sociais, relação professor-aluno e sala de aula.

\section{A Educação e a Pandemia COVID-19}

Nesta seção apresentaremos o que está ocorrendo no restante do planeta, quando temos o distanciamento social com as escolas compulsoriamente fechadas, impactando cerca de $87 \%$ da população estudantil do mundo, em um total de 182 países. Segundo a UNESCO como informação de caráter geral, apenas os seguintes países mantinham, em 30 de abril, as escolas abertas: Belarus, Turquemenistão, Tajiquistão, Burundi e Nicarágua.

\subsection{Aspectos verificados no mundo}

Nas seções a seguir, procuramos apresentar o que foi estabelecido em relação às

\footnotetext{
${ }^{4}$ Disponível em: https://pt.unesco.org/covid19/educationresponse. Acesso em: 29 abr. 2020.
} 
ações de políticas públicas no mundo, sendo que a China, foco inicial do COVID-19, ganhou uma amplitude maior em virtude de ser também, como o Brasil, um país de enormes desigualdades sociais e dimensões continentais. Além disso, partiu-se de Reimers e Schleicher (2020), que estudaram, entre os dias 18 a 27 de março, 98 países diferentes identificando as necessidades educacionais mais importantes e os desafios que vários sistemas educacionais enfrentam ao contar com a educação on-line como uma modalidade alternativa de ensino.

\subsubsection{República Popular da China}

A China possui o maior sistema educacional do mundo. Com quase 260 milhões de estudantes e mais de 15 milhões de professores em cerca de 514.000 escolas (NATIONAL Bureau of Statistics of China, 2014 apud ORGANIZAÇÃO PARA A COOPERAÇÃO E DESENVOLVIMENTO ECONÔMICO, 2016, p.9). A responsabilidade principal pela educação é dos condados, que gerenciam e oferecem ensino primário e secundário, enquanto o ensino superior fica sob a jurisdição das autoridades provinciais. Na China, os estudantes devem completar nove anos de escolaridade obrigatória. A educação primária começa aos seis anos para a maioria das crianças. Seguem-se três a quatro anos de ensino médio. Depois de concluir o ensino obrigatório, os alunos podem optar por continuar com o ensino médio.

Em relação ao fechamento das escolas e universidades ocorrido em 04 de fevereiro, o governo chinês, por intermédio do seu Ministério da Educação, estabeleceu a política pública emergencial "Suspensão das aulas sem interromper o aprendizado"5 (tradução livre). A política consiste em combater a propagação da epidemia, suspendendo o ensino nas escolas e voltando-se para a educação on-line (ZHANG et al., 2020). Uma situação apresentada pelas autoras foi se a educação on-line poderia substituir adequadamente a educação tradicional.

$\mathrm{Na}$ implementação dessa política, segundo essas autoras, foram realizados cinco movimentos: (i) integrar recursos e planejamento nacionais, com a manutenção de plataformas de serviço público e redes escolares em diferentes níveis; (ii) capacitação dos professores, fornecendo treinamento on-line; (iii) permitir que as autoridades e escolas locais realizem o ensino on-line de acordo com as suas condições; (iv) formular diretrizes para a preparação de uma transição suave de volta à educação tradicional após a pandemia; e (v) Elaborar um plano para reabertura da escola após a pandemia (ZHANG et al., 2020, grifos nosso). Interessante ponto a destacar foi que os professores foram aconselhados a utilização de recursos de ensino on-line em plataformas abertas, como os "Massive Open On-line Course" (MOOC), que na China são conhecidos como "Cursos Abertos Online da Elite

\footnotetext{
${ }^{5}$ Suspending Classes without Stopping Leaning
} 
Nacional ${ }^{\text {" }}$ (tradução livre).

Verificaram-se dificuldades na implantação dessa política, como: (i) o ensino on-line é limitado pela infraestrutura; (ii) a proporção e a eficiência do uso de recursos de ensino on-line ainda são bastante baixas; (iii) dependência da capacidade e experiência dos professores; (iv) professores e alunos enfrentam problemas de estudarem em casa (ZHANG et al., 2020, grifo nosso). Um questão exposta por Zhou e outros (2020, p.503, grifo nosso, tradução livre) é que "precisamos melhorar ainda mais a construção de plataformas de aprendizado on-line de escolas de ensino fundamental e médio, enriquecer continuamente os recursos de aprendizado e impedir que as salas de aula normais sejam copiadas [...]".

Para atender os alunos da zona rural e montanhosa, o governo chinês normatizou em primeiro lugar a utilização geral dos recursos de televisão e rede para a obtenção de vantagens complementares e compartilhamento de recursos de cobertura mais abrangente (ZHOU et al., 2020). Os 9.262 estudantes pobres do ensino médio da província de Guangdong, localizada na parte continental da China do Sul, receberam computadores tabletes para garantir o seu progresso na educação on-line. Foi estipulado que nenhum aluno ficaria para trás, inclusive por meio de métodos de ensino de áudio, como telefone e rádio, "[...] devemos prestar atenção aos alunos com dificuldades financeiras em casa e garantir que ninguém seja deixado para trás."7

O jornal internacional Toutiao, que apresenta diversas notícias da China, no dia 04 de março de 2020, apresentou uma matéria cujo título em tradução livre é "O que pode ser feito para aliviar o problema de 'estudantes pobres que não podem fazer cursos on-line?'”. A reportagem em sua introdução, informa-nos que um condado do oeste da China disse a repórteres que, após investigação, havia mais de 2.000 estudantes que não puderam ter aulas on-line por motivos como falta de smartphone, computador e internet. O autor da matéria foi enfático: "Os alunos pobres não podem participar de cursos on-line, o que merece nossa consideração"8.

O relatório do $19^{\circ}$ Congresso Nacional do Partido Comunista da China ${ }^{9}$ apontou que, para promover o desenvolvimento da integração da educação urbana e rural obrigatória, é necessário permitir que todas as crianças desfrutem de uma educação justa e de qualidade. Hoje, estamos cada vez mais conscientes de que a educação é a chave para adquirir

${ }^{6}$ The National Elite Online Open Courses (ZHANG et al., 2020, p.3).

7 要关注家庭经济困难学生, 确保不让一个学生掉队。Disponível em: http://news.southcn.com/nfplus/gdjytt/content/2020-03/02/content 190475992.htm. Acesso em: 28 abr. 2020. Tradução livre.

8 贫困生上不了网课，值得我们进一步思虑. Disponível em: https://toutiao.china.com/t 6LSr5Zuw55Sf5peg5rOV5LiK572R6K--.html. Acesso em: 28 abr. 2020. Tradução livre.

${ }^{9}$ Realizado no Grande Salão do Povo, em Pequim, entre 18 e 24 de outubro de 2017. Disponível em: http://portuguese.cri.cn/news/currentevents/409/20171020/42083.html. Acesso em: 03 maio 2020. 
conhecimento e promover um ponto de partida justo. "Internet + educação" pode permitir que crianças em áreas pobres ouçam as palestras de bons professores, expandam seus horizontes e aumentem suas ideias. Só alterando o atraso de algumas infraestruturas de informação rurais e a dificuldade de acesso é que as "crianças pobres podem mudar o seu destino através da educação e alcançar uma vida melhor"10.

Segundo Zhang et al. (2020), as seguintes lições futuras poderão ser vislumbradas como propostas de políticas públicas: (i) promover e melhorar as redes da informação educacional, a fim de atender a demanda de ensino on-line; (ii) equipar os professores e os estudantes com dispositivos eletrônicos padronizados para o ensino on-line; (iii) fornecer treinamento sistemático para os professores sobre o uso de plataformas on-line para ensino; (iv) apoiar e solicitar pesquisas em educação on-line; e (v) investigar a educação on-line especialmente no que diz respeito ao apoio ao aluno.

\subsubsection{Demais países pesquisados}

A base desta seção foi o estudo de Reimers e Schleicher (2020) já citado anteriormente. Porém, existe a necessidade de apresentar especificamente o que está ocorrendo na América Latina e Caribe, por isso mesmo também utilizamos o informe especial $n^{\circ} 1$ da COMISSÃO ECONÔMICA PARA A AMÉRICA LATINA (CEPAL) (2020) sobre os efeitos do COVID-19 em termos econômicos e sociais, além do documento oficial do Ministério de Educação Nacional da Colômbia aos seus docentes e estabelecimentos educativos.

O estudo de Fernando Reimers, do Harvard Graduate School of Education, e Andreas Schleicher, da OCDE, em suas 50 páginas, tem por objetivo apoiar as decisões educacionais para desenvolver e implementar respostas efetivas de educação para a Pandemia COVID-19. Os autores em seu resumo deixam claro que "na ausência de uma estratégia internacional e eficaz para proteger as oportunidades para aprender durante este período, esta interrupção causará graves perdas de aprendizado para os alunos" (REIMERS; SCHLEICHER, 2020, p.2, grifo nosso, tradução livre).

O informe da CEPAL (2020, p. 11, tradução livre) reforça que "A interrupção das atividades nas escolas terá efeitos significativos no aprendizado, especialmente para os mais vulneráveis". O que também é reforçado pelo governo colombiano ao considerar que cada proposta e cada decisão deve considerar "as condições em que meninos, meninas, adolescentes, jovens e suas famílias vivem hoje, seus sentimentos, suas experiências e as lições que podem ser derivadas para continuar seu processo de desenvolvimento e aprendizado durante e após o isolamento obrigatório". (COLÔMBIA, 2020, p.3, grifo nosso, tradução livre).

\footnotetext{
10 农村孩子上网难的现状，贫困孩子才能更好地通过教育改变命运，实现出彩人生。Disponível em: https://toutiao.china.com/t 6LSr5Zuw55Sf5peg5rOV5LiK572R6K--.html. Acesso em: 28 abr. 2020. Tradução livre.
} 
Reimers e Schleicher (2020, p.14, grifo nosso, tradução livre) argumentam que já existe uma perda considerável de aprendizagem durante as férias de verão. No caso dessa interrupção prolongada, sem uma data de retorno às atividades formais educacionais na escola, haverá uma perda de aprendizagem e também de conhecimentos e habilidades adquiridas. A conjuntura atual de fechamento das escolas e o distanciamento social urgiu desafios e estratégias alternativas ao ensino presencial. Uma conclusão que este autor também corrobora é que "a Pandemia atual é uma oportunidade para aumentar o envolvimento das famílias e apoiá-las na aquisição de competências para que exerçam uma paternidade mais afetiva e efetiva".

As principais contribuições, em síntese e dentro do escopo deste estudo, foram: (i) estabelecer um comitê gestor para desenvolver e implementar a resposta educacional; (ii) garantir o aprendizado acadêmico e dar apoio emocional aos alunos e ao corpo docente; (iii) priorizar os objetivos curriculares; (iv) identificar os meios de ensino; (v) definir claramente os papéis dos professores; (vi) criar um sitio para comunicação entre professores, alunos e responsáveis sobre objetivos curriculares, estratégias e sugestões de atividades e recursos adicionais; (vii) estratégias de educação on-line, e se esta não for viável, incluir programas de TV; (viii) assegurar apoio adequado aos estudantes e famílias mais vulneráveis durante o plano de educação alternativa; (ix) as escolas devem desenvolver um sistema de comunicação com cada aluno; e $(x)$ o uso seguro do tempo de tela e ferramentas on-line para preservar o bem-estar e a saúde mental dos estudantes.

Em relação às recomendações dos autores, a primeira é conspícua ao tema deste estudo: "os líderes educacionais devem adotar uma abordagem proativa para contribuir para a mitigação do impacto da Pandemia e para prevenir a perda de aprendizagem durante o período de distanciamento social necessário" (REIMERS; SCHLEICHER, 2020, p.10, grifo nosso, tradução livre). Um ponto recorrente nas recomendações tratou do currículo escolar, sendo esse um período de exceção e disruptura, há a necessidade de reorientação das metas curriculares, que em suma quer dizer: chegar a um denominador comum do que deve ser ensinado e aprendido pelos estudantes.

Não nos cabe apresentar todo o relatório de Reimers e Schleicher, mas uma pergunta retrata bem o que este estudo se propôs: Quais necessidades os 330 entrevistados identificaram como mais críticas neste momento? O maior percentual de respostas caminhou por "garantir o aprendizado acadêmico para os alunos, apoiar os alunos que não possuem habilidades para estudo independente, garantir o bem-estar dos alunos, fornecer suporte profissional aos professores e garantir o bem-estar dos professores, assim como assistência médica" (REIMERS; SCHLEICHER, 2020, p.23, grifo nosso, tradução livre).

O Ministério de Educação Nacional da Colômbia (2020, p.6) lembra aos seus setores educacionais e docentes "de que o serviço educacional será prestado nas residências e que 
suas estratégias serão integradas ao cotidiano das famílias (de alunos e professores) que enfrentam uma situação isolada e ao desenvolvimento de rotinas de cuidados e higiene que protegem suas vidas."

O importante ponto a ser destacado foi a necessidade de um equilíbrio entre as atividades digitais e as sem tela. No relatório do PISA 2018, cerca de 9\% dos estudantes de 15 anos não têm sequer um lugar tranquilo para estudar. Um dos desafios expostos pelos entrevistados foi a disponibilidade de infraestrutura tecnológica. O aprendizado on-line requer, além da ferramenta digital (desktops, tablets, notebook, smatphone etc), o acesso à internet e um lugar específico para estudar. No boletim da CEPAL (2020, p.11), sobre o mesmo tema, "existem disparidades no acesso a dispositivos digitais e Internet de banda larga entre populações urbanas e rurais, entre os sexos, entre populações que falam ou não a língua oficial (espanhol ou português) e entre populações com e sem deficiência.".

A América Latina enfrenta desafios na formação de professores em Tecnologia de Informação e Conhecimento (TIC). Por exemplo, no Brasil em 2018, apenas $20 \%$ dos professores participaram de um curso de educação continuada para o uso de computadores e da Internet para o ensino. "Em relação ao uso da Internet, $16 \%$ relataram que a usavam uma ou mais vezes ao dia; enquanto $20 \%$ o fazem uma vez por semana e $18 \%$ pelo menos uma vez por mês". (COMITÊ DE GESTÃO DA INTERNET NO BRASIL, 2019 apud CEPAL, 2020, p.11). No mesmo diapasão, os autores Reimers e Schleicher (2020, p.31) destacam que "[...] as enormes necessidades de formação daqueles que estão à frente dos sistemas educacionais para se prepararem para o uso da tecnologia educacional".

Em relação ao tema currículo e o que deve ser ministrado, os professores colombianos foram avisados que durante a Pandemia COVID-19, o desenvolvimento do conteúdo deve ser revisto no plano de estudos que foi concebido para ser desenvolvido pessoalmente, para tempos e circunstâncias não normais. Devemos motivar e aprimorar suas capacidades, aproveitando sua experiência de vida, conhecimentos familiares e culturais, sonhos e projetos, a fim de definir mecanismos de comunicação e monitoramento de estabelecimentos de ensino para apoiar a continuidade do processo educacional em casa.

A questão do meio copo cheio aparece: Existe um lado positivo do momento vivido por todos no campo da educação? Segundo os autores Reimers e Schleicher (2020) seriam a possibilidade de introdução de tecnologias e outras soluções inovadoras e com certeza um aumento na autonomia dos alunos para gerenciar seu próprio aprendizado. O documento do Ministério de Educação Nacional da Colômbia também assevera que o momento é de "fortalecer a autonomia, tomar decisões responsáveis e motivar neles a esperança de fortalecer seus projetos de vida" (COLOMBIA, 2020, p. 15, tradução livre). Esse documento também cita o objetivo 4 da agenda de Desenvolvimento Sustentável (Educação de Qualidade), que reconhece o potencial humano da aprendizagem ao longo da vida: aprenda sempre, em qualquer lugar, em qualquer tipo de espaço e por todos os meios possíveis. 


\subsection{Aspectos verificados no Brasil}

Iniciamos pelo Quadro 1, constante da Revista da Universidade Federal do Rio de Janeiro (UFRJ) (2020, p.11-13), em que são expostas as ações de 22 estados brasileiros e Brasília no contexto da Pandemia COVID-19, não sendo citados Paraná, Roraima, Tocantins e Paraíba. Porém, para termos uma ideia do que está ocorrendo em certa medida das ações públicas, o número de estados representados nos é atendido. O que podemos verificar de imediato é que cada município tem uma solução para o seu problema de fechamento das escolas e a continuação da aprendizagem do seu estudante.

Em relação às plataformas de apoio desenvolvidas para o ensino on-line, dos respondentes: (i) dezesseis se utilizam da plataforma Rede Escola ${ }^{11}$, que foi desenvolvida pelos Institutos Natura, Inspirare e Fundações Lemann, Vanzolini e Telefônica Vivo; (ii) cinco estados se utilizam da plataforma Google Classroom ${ }^{12}$; e (iii) o Estado da Bahia da plataforma Anísio Teixeira pertencente ao próprio governo baiano. O estado do Rio Grande do Norte está disponibilizando para a aprendizagem a distância tanto da Rede Escola como do Google. O Piauí é o único estado que não apresenta informações do uso de plataformas digitais de aprendizagem, "As escolas utilizam aulas com transmissão ao vivo pela internet, gravadas para a televisão, lista de exercícios por e-mail, fóruns de discussão" (UNIVERSIDADE FEDERAL DO RIO DE JANEIRO, 2020, p.12).

Existem diversos programas inerentes e específicos em cada rede de ensino estadual. No Amazonas, por exemplo, um estado cuja via de comunicação e deslocamento é o rio, existe o "Programa Aula em Casa", que se utiliza da retransmissão de programas em três canais de TV aberta, conforme apresentado pelo estudo da UFRJ citado anteriormente. A Secretaria de Educação de Goiás desenvolveu um portal "Net Escola", onde disponibiliza textos, vídeos e listas de exercícios. Outro exemplo é o estado do Pará que implementou o "Projeto Todos em Casa pela Educação", com transmissão de conteúdos por canal de TV aberta.

O que podemos verificar no Brasil é a utilização de plataformas de pacotes de conteúdos educacionais e a utilização dos canais de TV aberta. Para aqueles alunos que não têm acesso a internet, estados produziram atividades impressas que são enviadas via

\footnotetext{
${ }^{11}$ A plataforma é uma ferramenta de apoio muito importante para nos auxiliar no processo ensino aprendizagem, enriquecendo o conhecimento dos alunos. Disponível em: https://escoladigital.org.br/planos-de-aula/plataforma. Acesso em: 04 maio 2020.

12 O Google Classrom ou sala de aula é um serviço gratuito para escolas, organizações sem fins lucrativos e qualquer usuário que tenha uma Conta do Google pessoal. Com o Google Sala de aula, os professores e alunos se conectam facilmente, dentro e fora das escolas. O Google Sala de aula economiza tempo e papel, além de facilitar a criação de turmas, distribuição de tarefas, comunicação e organização. Disponível em:

https://play.google.com/store/apps/details?id=com.google.android.apps.classroom\&hl=pt BR. Acesso em: 04 maio 2020.
} 
correios. Um fato relevante em relação ao Distrito Federal e aos estados do Amapá e Minas Gerais, é que foram os únicos que citaram oferecerem curso de capacitação ou treinamento para educadores para utilização de plataformas on-line.

Sendo este autor do Rio de Janeiro, foi possível o acesso ao documento emanado pela Secretaria de Educação, que em suma trata das medidas tomadas pela própria SEEDUC em consonância com recomendações da UNESCO, ou seja, a busca por "atividades de aprendizagem remota, mediadas pelos professores da Rede e fazendo uso de diversas tecnologias e abordagens que garantiriam maior mobilização e engajamento de todos: alunos, professores e pais". (RIO DE JANEIRO, 2020, p.3). As propostas foram:

1. Salas de aulas virtuais no Sistema de Gestão de Aprendizagem Google Classroom, garantindo a autonomia pedagógica de professores e o controle de atividades desenvolvidas;

2. Disponibilização de Material Didático impresso (mídia impressa);

3. Divulgação de conteúdo pedagógico via Televisão - Canal Futura (tele- aprendizagem); e TV Aberta e TV Alerj (tele- aprendizagem); e

4. Mediação de equipe pedagógica para contato direto com os estudantes.

O professor seria o condutor e mediador do ensino, propondo a criação de trilhas de aprendizagem que podem e devem ser enriquecidas com o uso de variadas ferramentas educacionais. "Ressalte-se que é tempo para a aprendizagem mais flexível, bem menos conteudista, mas alinhada com o Currículo Básico e a Base Nacional Comum Curricular" (RIO DE JANEIRO, 2020, p.4).

No documento da Secretária de Educação, em que a aprendizagem móvel (mobile learning) é a via de aprendizagem durante o fechamento das escolas e distanciamento físico, aos estudantes com dificuldades de acesso à internet seria garantido o uso de seus aparelhos de telefonia e de dados móveis, pois haveria a disponibilização de "chips" com pacote de dados de Internet para que todos os professores e alunos tenham a oportunidade de utilizar os recursos digitais para fins pedagógicos. Não foi possível depreender a real capacidade e conhecimento dos professores no trato das ferramentas digitais disponíveis, ou mesmo, se houve a sua capacitação.

\section{Resultados e Discussões}

A sala de aula é o lócus onde a relação professor-aluno se desenvolve em maior intensidade, em princípio, em todo o processo de ensino-aprendizagem. "A gestão da sala de aula supõe um gesto que se apoie, ao mesmo tempo, nos saberes a construir, nos procedimentos de implementação das atividades e na lógica das interações alunos com o mestre" (HONORATO, 2020, p.4). Outro ponto prejudicado é a relação direta professor-aluno. Importante aspecto dessa relação é que a conduta do professor influencia diretamente sobre a motivação e a dedicação dos seus alunos ao aprendizado. 
O imperativo mandatório do desempenho é deslocado para o espaço virtual, onde só alguns têm acesso e aptidão (DALTRO; SEGUNDO, 2020, p.7). Essa relação se distancia, fica mediada pelo ensino remoto. Precisamos procurar uma nova forma de ensinar e aprender pautada no contexto do mundo atual e considerando o que se tem em casa, o envolvimento da família e a vida de distanciamento social. Conteúdo sem contexto não gera significado. Isso sempre foi (e continua sendo) verdade na aprendizagem, por isso se faz necessária uma rotina positiva para apoiar os alunos neste momento de incerteza. ${ }^{13}$

Ocorre um aumento nas atividades do professor, um sujeito que em sua formação acadêmica não foi preparado no trato das novas ferramentas de aprendizagem digital. Este autor analisou os currículos de licenciatura em Pedagogia, História, Português, Matemática e Ciências Biológicas da UFRJ. Não foram encontradas disciplinas ligadas a EaD ou informática aplicada à educação nas licenciaturas de História e Português. Em Ciências Biológicas, em turma semipresencial, foi encontrada a disciplina de Introdução à Informática, ministrada à distância. A licenciatura em Matemática apresentou a disciplina de Computação, com foco em programação. Em Pedagogia, as três disciplinas encontradas eram optativas, a saber: Educação a Distância, Informática Aplicada à Educação e Educação e Novas Tecnologias. Mesmo sendo optativa, o ponto positivo foi a disciplina de Informática Aplicada à Educação, com 45 tempos de carga horária, trata do tema da formação de professores, recursos tecnológicos e softwares educativos.

Os nossos docentes não são preparados durante sua formação para a utilização das novas Tecnologias Digitais da Informação e Comunicação, e em especial as redes sociais como ferramenta educacional. Em diálogo via WhatsApp com o Professor Carlos Bravo Reyes, conseguimos o currículo de formação superior em Ciências da Educação da Universidad Autónoma Gabriel René Moreno, na qual a disciplina de Tecnologia Educativa é lecionada no último período da graduação. Da leitura do documento curricular, podemos extrair pontos importantes para a licenciatura nacional, como claro que há a necessidade do uso estratégico e inovador de recursos tecnológicos para melhorar a qualidade do processo educacional.

Este autor como professor e interessado, participou de aulas sobre o WhatsApp Open Online Course (WOOC), do Professor Carlos Bravo Reyes, da Bolívia. O curso é livre e aberto aos docentes em geral, suas bases didáticas são a micro aprendizagem, os micros conteúdos e o micro meio. Utiliza-se preferencialmente o smartphone para o ensino dos alunos. Outra metodologia de aprendizagem e divulgação de aulas via as redes sociais é o Massive Open

\footnotetext{
${ }^{13}$ Disponível em: https://jornadaedu.com.br/na-agenda-edu/a-jornada-educacional-continua-ummanifesto-da-agendaedu/?utm campaign $=a$ jornada educacional continua comercial\&utm medium=email\&utm source $=\mathrm{RD}+$ Station. Acesso em: 04 maio 2020.
} 
Online Course (MOOC), sendo utilizado a plataforma do Facebook. Também é disponibilizado este curso gratuitamente na internet.

Segundo Relatório Digital de 2019 ${ }^{14}$, existem 215,2 milhões de conexões móveis no Brasil, o que representa uma penetração de $102 \%, 81 \%$ dos brasileiros com 13 anos ou mais estão ativos nas redes sociais e o Brasil está em segundo lugar em termos de horas gastas em plataforma de redes sociais por dia: $3 \mathrm{~h}$ e $34 \mathrm{~min}$. As redes sociais mais utilizadas são Youtube, 95\%; Facebook, 90\%; WhatsApp, 89\%; e Instagram com 71\%.

O clima socioemocional na sala de aula é tão importante para o ensino e a aprendizagem, e na situação atual a relevância na sala de jantar ou outro ambiente familiar em que momentos de diálogos podem ser criados pela quarentena. Educadores, professores e pais descobrem aulas on-line, a falta de políticas públicas nesse setor e o desafio de tentar criar alguma forma de rotina familiar nessa nova maneira de viver isolados socialmente.

As condições objetivas de acesso ao material pedagógico criarão tratamentos diferenciados entre aqueles que acessam e não acessam as tecnologias digitais. Em recente reportagem do jornal O Estado de São Paulo, a jornalista Anna Barbosa, em 26 de abril, apresentou o tema da EaD no pós-pandemia, em que as plataformas de ensino a distância veem dobrar o número de clientes e abrem oportunidades para novos negócios. As empresas que trabalham nessa fatia de mercado, ou seja, o educacional, são conhecidas como edtechs, que são 434 no Brasil' ${ }^{15}$, e não param de crescer, uma questão importante para futuras discussões.

Em estudo do Banco Mundial intitulado: "Pobreza na aprendizagem: como mudar isso?", é apresentado o conceito de aprendizagem da pobreza, onde "Todas as crianças devem poder ler aos 10 anos" (BANCO MUNDIAL, 2019, p.5, tradução livre). A motivação da publicação desse estudo foi pelo atingimento das metas estabelecidas para 2030 dos objetivos para o desenvolvimento sustentável no planeta da Organização das Nações Unidas ${ }^{16}$. Assim, sem uma base sólida em alfabetização, crianças e jovens não podem prosperar mais tarde na escola ou no local de trabalho, pois carecem das habilidades e do capital humano necessários para alimentar suas carreiras e economias.

A temática sobre se o currículo precisa ser cumprido ou em sua plenitude não ganha espaço quando não temos como prever o término da quarentena com a abertura das escolas. Segundo Schmidt (2003, p.60), "O currículo é o próprio fundamento de qualquer sistema de ensino, ele é o elemento nuclear do projeto pedagógico da escola, viabilizando o processo de ensino e aprendizagem". Assim, a primeira preocupação dos gestores educacionais seria pelo seu cumprimento, mesmo que pelo ensino remoto. Tal situação se torna improdutiva, pois

14 Disponível em: https://www.pagbrasil.com/pt-br/insights/relatorio-digital-in-2019-brasil/. Acesso em: 04 maio 2020.

${ }^{15}$ Disponível em: http://conteudo.distrito.me/distrito-dataminer-edtech-report. Acesso em: 04 maio 2020.

${ }^{16}$ Disponível em: https://nacoesunidas.org/pos2015/agenda2030/. Acesso em: 04 maio 2020. 
conteúdos serão massificados nos estudantes sem uma avaliação da sua aprendizagem, pois o currículo previsto para uma escola presencial não se alinha com a metodologia de uma educação a distância, principalmente pelos fatos já citados anteriormente.

Ao escolher entre alternativas seguras para a aprendizagem dos nossos estudantes, devemos nos perguntar não apenas como superar a ameaça imediata, mas também que tipo de mundo habitaremos quando a tempestade passar, uma importante reflexão. Roesler e Pandolfo (2020, grifo nosso) apresentam o que é preciso fazer para não parar o calendário letivo: (i) Defina o modelo a ser utilizado: síncrono ou assíncrono; (ii) Escolha as plataformas; (iii) Capacite professores e alunos; (iv) Comunique intensamente todos os envolvidos; (v) Acompanhe e avalie; (vi) Cronograma semanal de estudos; (vii) as sessões de aulas; (viii) a postagem dos conteúdos de estudos; (ix) a entrega e o recolhimento das tarefas e atividades; $(x)$ sessões de dúvidas dos alunos; (xi) Mesmo que virtualmente (olho no olho); (xii) Crie informativos e anúncios; (xiii) Tenha um canal de atendimento; e (xiv) Verifique o aprendizado por meio de avaliações.

\section{Considerações Finais}

A crise inicialmente sanitária mostrou a profunda transformação que os sistemas educacionais precisaram para se adaptar as escolas fechadas e distanciamento social, e procurar soluções para que a aprendizagem de todos os estudantes não seja prejudicada. Ao agirmos de forma apressada em soluções paliativas e improvisadas, apenas estamos adiando um problema e colocando nos ombros dos professores, estudantes e família o ônus de continuar o ensino, em ambiente que nem sempre é o apropriado, que nem sempre é o desejado, que nem sempre atende aos anseios tecnológicos de um ensino remoto, que nem sempre conseguirá atingir um mínimo de qualidade na aprendizagem do estudante, ainda mais que suas relações sociais e educacionais estão prejudicadas pela falta de olho no olho do professor, do espaço lúdico e amigo do recreio, das brincadeiras e da sala de aula.

Conforme descrito na epígrafe introdutória, todos nós, independente de que local no mundo habitemos, temos bom senso, em menor e maior grau, mas todos temos. Diversas lições podem ser desveladas no campo da educação do que está acontecendo com o fechamento das escolas. O que não está correto é o improviso ou mesmo a falta de um mínimo discernimento quando tratamos, em especial, de crianças e jovens que precisam ser guiados pelos familiares, professores, todos que, em certa medida, estão construindo um cidadão social, crítico, autônomo e com ações positivas e ativas em nossa sociedade. O maior desafio está na seguinte afirmativa: Educação não se improvisa.

As seguintes lições, portanto, podem ser desveladas: (i) necessidade de se estabelecer um plano alternativo para o fechamento das escolas e a continuação das aulas; 
(ii) Os cursos virtuais são diferentes e são preparados no tempo e espaços e em uma situação muito diferente daquela em que estamos agora; (iii) despreparo dos professores para as novas tecnologias educacionais; (v) programas de aumento na adoção de ferramentas digitais por escolas e por professores; (vii) uma política pública de democratizar o acesso à internet para as famílias em todo o Brasil; (viii) aproveitamento do EaD como metodologia viável e de qualidade também na educação básica, um ensino se possível híbrido; (ix) condução de orientações de aprendizado e aulas por meio do uso da televisão aberta, por exemplo; e (xi) revisão dos marcos regulatórios da $\mathrm{EaD}$, de forma que os pacotes de ensino remoto de entidades empresariais ou startups sejam primeiramente avaliados e em seguida reconhecidos como uma alternativa à instrução presencial na contagem dos dias letivos.

A escola tornou-se um lócus importante e essencial no funcionamento diário das sociedades, não apenas para os professores e estudantes, mas com certeza para as famílias e seu entorno geográfico e informal. A passagem das atividades formais e presenciais para a virtual, infere-se que trará diversas consequências, em especial um aumento nas desigualdades educacionais. Devemos refletir acerca de tudo que está acontecendo e, no final, procurarmos não repetir os mesmos erros e transmitir adequadamente os possíveis acertos, pois sabemos que a tecnologia é importante, mas não é tudo.

Termino com uma frase de Paulo Freire (2008, p.26) que pode ser muito bem contextualizada aos dias atuais: "E essas condições implicam ou exigem a presença de educadores e de educandos criadores, instigadores, inquietos, rigorosamente curiosos, humildes e persistentes", porque temos condições de reforçar as costuras da educação de qualidade, com aprendizagem verdadeira, retirando, posteriormente, os alinhavos que ficaram. Precisamos voltar a ter vida própria.

\section{Referências}

BANCO MUNDIAL. Ending learning poverty: What will it take? 2019. Disponível em: https://openknowledge.worldbank.org/handle/10986/32553. Acesso em: 30 abr. 2020.

BRASIL. Decreto no 9.057, de 25 de maio de 2017. Dispõe sobre a oferta de cursos na modalidade a distância. As instituições de ensino superior deverão obter credenciamento para oferta de cursos de graduação, pós-graduação e lato sensu. Diário Oficial da União - Seção 1 - 26 maio 2017, Página 3 (Publicação Original).

COLÔMBIA. Ministerio de Educación. Sector Educativo al Servicio de la vida: juntos para Existir, Convivir y Aprender. 2020. Disponível em: https://www.mineducacion.gov.co/1759/articles-394577 recurso 3.pdf. Acesso em: 29 mar. 2020.

COMISSÃO ECONÔMICA PARA A AMÉRICA LATINA [CEPAL]. América Latina y el Caribe ante la pandemia del COVID-19: Efectos económicos y sociales. Informe Especial COVID19, n.1, 2020. Disponível em: https://www.cepal.org/es/publicaciones/45337-america-latinacaribe-la-pandemia-covid-19-efectos-economicos-sociales. Acesso em: 20 abr. 2020.

DALTRO, M.; SEGUNDO, J. de D. B. A pandemia que nos mostra quem somos? Rev. Psicol. 
Divers. Saúde, Salvador, v.9, n.1, p.5-8, 2020. Doi: 10.17267/2317 3394rpds.v9i1.2844 | ISSN: 2317-3394.

FREIRE, P. Pedagogia da autonomia: saberes necessários à prática educativa. 37. ed. São Paulo: Paz e Terra, 2008. (Coleção Leitura).

GIL, A. C. Como elaborar projetos de pesquisa. 5. Ed. São Paulo: Atlas, 2010.

HONORATO, H. G. (no prelo). A educação brasileira e a pandemia covid-19: alinhavos entre o ensino remoto e a aprendizagem dos estudantes. 2020.

LIBÂNEO, J. C. As teorias pedagógicas modernas revisitadas pelo debate contemporâneo na educação. LIBÂNEO, J. C.; SANTOS, A. (org.). Educação na era do conhecimento em rede e transdisciplinaridade. Campinas: Alínea, 2005. p.16-58.

MILL, D. Docência virtual: uma visão crítica. Campinas: Papirus, 2012. (Coleção Papirus Educação).

MORAN, J. M. O que é educação à distância. São Paulo: USP, 2002. Disponível em: http://www2.eca.usp.br/moran/wp-content/uploads/2013/12/dist.pdf. Acesso em: 22 nov. 2017.

OLIVEIRA, M. M. de. Como fazer pesquisa qualitativa. 7. ed. ver. e atual. Petrópolis, RJ: Vozes, 2016.

ORGANIZAÇÃO DAS NAÇÕES UNIDAS PARA A EDUCAÇÃO, A CIÊNCIA E A CULTURA [UNESCO]. O Futuro da aprendizagem móvel: implicações para planejadores e gestores de políticas. Brasília: UNESCO, 2014. ISBN: 978-85-7652-188-4

ORGANIZAÇÃO PARA A COOPERAÇÃO E DESENVOLVIMENTO ECONÔMICO [OCDE]. Education in China: a snapshot. 2016. Disponível em: https://www.oecd.org/china/Educationin-China-a-snapshot.pdf. Acesso em: 17 abr. 2020.

REIMERS, F. M.; SCHLEICHER, A. Un marco para guiar una respuesta educativa a la pandemia del 2020 del COVID-19. Enseña Peru. Tradução para o espanhol de Sergio Cárdenas, Víctor Granados, Dulce Lomelí e Ignacio Ruelas. 2020. Disponível em: https://globaled.gse.harvard.edu/files/geii/files/un marco para guiar una respuesta educat iva a la pandemia del 2020 del covid-19 .pdf. Acesso em: 18 abr. 2020.

RIO DE JANEIRO. Secretaria de Estado de Educação [SEEDUC]. Declaração pela Aprendizagem em Tempo de pandemia na Secretaria de Estado de Educação do Rio de Janeiro. 2020. Disponível em: http://abre.ai/a3J2. Acesso em: 25 abr. 2020.

ROESLER, J.; PANDOLFO, J. COVID19 e a reinvenção da sala de aula. Hoper Educação. 2020. Disponível em: https://www.hoper.com.br/crise-do-covid19. Acesso em: 02 maio 2020.

SCHMIDT, E. S. Currículo: uma abordagem conceitual e histórica. Publ. UEPG Ci. Hum., Ci. Soc. Apl., Ling., Letras e Artes, Ponta Grossa, PR, v.11, n.1, p.59-69, jun. 2003.

UNIVERSIDAD AUTÓNOMA GABRIEL RENÉ MORENO FACULTAD DE HUMANIDADES. Carrera de Ciencias de la Educación. Rediseño de la Licenciatura en Ciencias de la Educación. ago. 2016 Santa Cruz de La Sierra, Bolivia. 
UNIVERSIDADE FEDERAL DO RIO DE JANEIRO [UFRJ]. Em defesa da educação pública comprometida com a igualdade social: porque os trabalhadores não devem aceitar aulas remotas. Coletivo de Estudos em Marxismo e Educação [Colemarx]. Programa de Pós-Graduação em Educação [PPGE] da Faculdade de Educação. 22 abr. 2020. Disponível em: http://www.colemarx.com.br/artigos-produzidos/. Acesso em: 22 abr. 2020.

ZHANG, W. et al. Suspending Classes Without Stopping Learning: China's Education Emergency Management Policy in the COVID-19 Outbreak. Journal of Risk and Financial Management, v.13, n. 55, p.1-6, mar. 2020. doi:10.3390/jrfm13030055.

Disponível em: https://www.mdpi.com/1911-8074/13/3/55. Acesso em: 28 mar. 2020.

ZHOU, L. et al. "School's Out, But Class's On”, The Largest Online Education in the World Today: Taking China's Practical Exploration During The COVID-19 Epidemic Prevention and Control as An Example. Best Evid Chin Edu, v.4, n.2, p.501-519, mar. 2020. Disponível em: https://ssrn.com/abstract=3555520 